\title{
Modeling and Analysis of a Cascaded Battery-Boost Multilevel Inverter Using Different Switching Angle Arrangement Techniques
}

\author{
Usman Bashir Tayab \\ School of Electrical System Engineering \\ University Malaysia Perlis \\ Perlis, Malaysia \\ usman.tayab@yahoo.com
}

\author{
Md. Abdullah Al Humayun \\ School of Electrical System Engineering \\ University Malaysia Perlis \\ Perlis, Malaysia \\ humayun0403063@gmail.com
}

\begin{abstract}
Multilevel inverters have the capability to produce an AC staircase output waveform without using a bulky passive filter. Therefore, the multilevel inverters are gaining more and more popularity, among the different types of inverters, for photovoltaic applications in the modern era of technology. However, if the switching angle arrangement technique is not selected appropriately then the total harmonic distortion of the voltage output waveform may become undesirable. In this paper, Half-Equal-Phase, Feed-Forward and Selective Harmonics Elimination Pulse Width Modulation switching angle arrangement techniques at different power factors (i.e., 1.0, 0.75 and 0.50) are applied to a cascaded battery-boost inverter. PSIM software is used to evaluate and compare the performance of a 9level cascaded battery-boost inverter with three switching angle arrangement techniques at power factors of $1.0,0.75$, and 0.50 , respectively. Simulation results show that the Selective Harmonics Elimination Pulse Width Modulation technique can produce an output voltage and current waveform with the lowest total harmonic distortion. On the other hand, the output current waveform produced by power factor 0.50 had the lowest total harmonic distortion.
\end{abstract}

Keywords-half-equal-phase method; multilevel inverter; switching angle; selective harmonics elimination pulse width modulation; total harmonic distortion.

\section{INTRODUCTION}

Solar energy is probably the dominant renewable energy source available nowadays. The electric power generated by photovoltaic (PV) panels is obtained in DC form. Therefore, it needs to be converted into AC form using a power inverter [1, 2]. Several inverter topologies have been proposed in the past and each inverter topology has different characteristics. The conventional inverter requires a bulky filter to produce a sinusoidal AC voltage waveform [3]. Recently, multilevel inverters gained popularity. Unlike the conventional inverters, the multilevel inverter does not require bulky filters to generate a near sinusoidal AC output waveform $[4,5]$.

The concept of multilevel inverters has been introduced in 1975. With the development of the new technologies, the first multilevel inverter was proposed in 1981 which was actually a 3-level inverter [6]. The basic multilevel inverter can be divided into three types such as: diode-clamped, flyingcapacitor and cascaded battery-boost multilevel inverter. Among these three types of multilevel inverters, the cascaded battery-boost multilevel inverter is gaining popularity for stand-alone PV systems [7]. However, if the proper switching angle arrangement technique is not applied then the resulted total harmonic distortion (THD) of cascaded battery-boost multilevel inverter may become unacceptable. Therefore, in this paper three different types of switching techniques are presented. The main switching angle drives using Half-EqualPhase (HEP), Feed-Forward (FF) and Selective Harmonics Elimination Pulse Width Modulation (SHEPWM) techniques are applied to a 9-level cascaded battery-boost inverter.

\section{MethodolOGY}

\section{A. Cascaded Battery-Boost Multilevel Inverter}

The cascaded battery-boost multilevel inverter was proposed in [8] and it has become the most popular inverter topology in standalone PV systems. Figure 1 shows the block diagram of a cascaded battery-boost multilevel inverter.

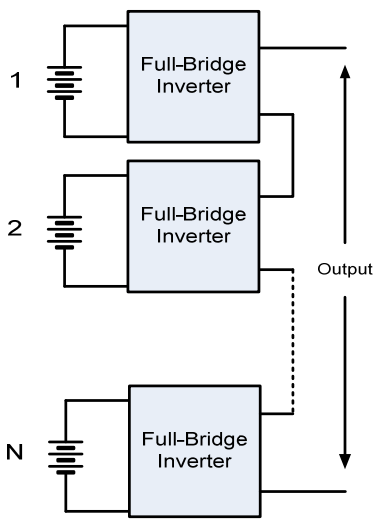

Fig. 1. Cascaded battery-boost multilevel inverter.

The full-bridge inverters are connected in series with their output voltages summed up and hence, the final voltage boosting capability. It is highly reliable with low voltage 
unbalance problems. With $\mathrm{N}$ number of full-bridge inverters, the output staircase AC voltage produced consists of $2 \mathrm{~N}+1$ levels [9]. This inverter topology requires a separate DC source for each full-bridge as seen in Figure 1.

\section{B. Power Factor}

The power factor (PF) can be expresses as the ratio between the resistance and the impedance or the cosine of the phase angle between current and voltage. Table I shows the value of resistor (R), frequency (f) and inductor (L) at different power factors.

TABLE I. PARAMETERS VALUE AT DIFFERENT POWER FACTOR

\begin{tabular}{|c|c|c|c|}
\hline Parameter & $\mathrm{PF}=0.50$ & $\mathrm{PF}=0.75$ & $\mathrm{PF}=1.0$ \\
\hline $\mathrm{R}$ & $10 \Omega$ & $10 \Omega$ & $10 \Omega$ \\
\hline $\mathrm{L}$ & $55.13 \mathrm{mH}$ & $28.075 \mathrm{mH}$ & 0 \\
\hline $\mathrm{f}$ & $50 \mathrm{~Hz}$ & $50 \mathrm{~Hz}$ & $50 \mathrm{~Hz}$ \\
\hline
\end{tabular}

\section{Switching Angle Arrangement Techniques}

The multilevel inverters have various topologies and a wide range of advantages. However, the exiting topologies are unable to produce a pure sinusoidal output waveform as long as the switching angles are not appropriately arranged [10]. In order to obtain good power quality and low THD, three different switching angle arrangements techniques are carefully investigated.

Figure 2 shows the output voltage waveform for an m-level multilevel inverter. For an $\mathrm{m}$-level waveform in the period $(0-$ $2 \pi)$, there are $2(\mathrm{~m}-1)$ switching angles to be determined. The switching angles are defined as shown in (1) by the time sequence. The sine wave is dividing into four quadrants. The switching angles in $1^{\text {st }}$ quadrant period $(0-\pi / 2)$ are defined as main switching angles.

$$
\theta_{1}, \theta_{2}, \ldots \ldots \theta_{m-2}, \theta_{m-1}
$$

For an m-level ( $\mathrm{m}$ is an odd number) waveform, the main switching angles are (m-1)/2.

The main switching angles in $1^{\text {st }}$ quadrant (i.e., $0-\pi / 2$ ) are:

$$
\theta_{1}, \theta_{2}, \ldots \ldots \theta_{(m-1) / 2}
$$

The switching angles in the $2^{\text {nd }}$ quadrant (i.e., $\left.\pi / 2-\pi\right)$ ) are:

$$
\theta_{(m-1) / 2}=\pi+\theta_{1}
$$

The switching angles in the $3^{\text {rd }}$ quadrant (i.e., $\pi-3 \pi / 2$ ) are:

$$
\theta_{m}=\pi+\theta_{(m-1) / 2}
$$

The switching angles in the $4^{\text {th }}$ quadrant (i.e., $3 \pi / 2-2 \pi$ ) are:

$$
\theta_{(3 m-1) / 2}=2 \pi-\theta_{1}
$$

For the analysis, only main switching angles need to determine. The other switching angles can be derived from the main switching angles in the $1^{\text {st }}$ quadrant $(0-\pi / 2)$.

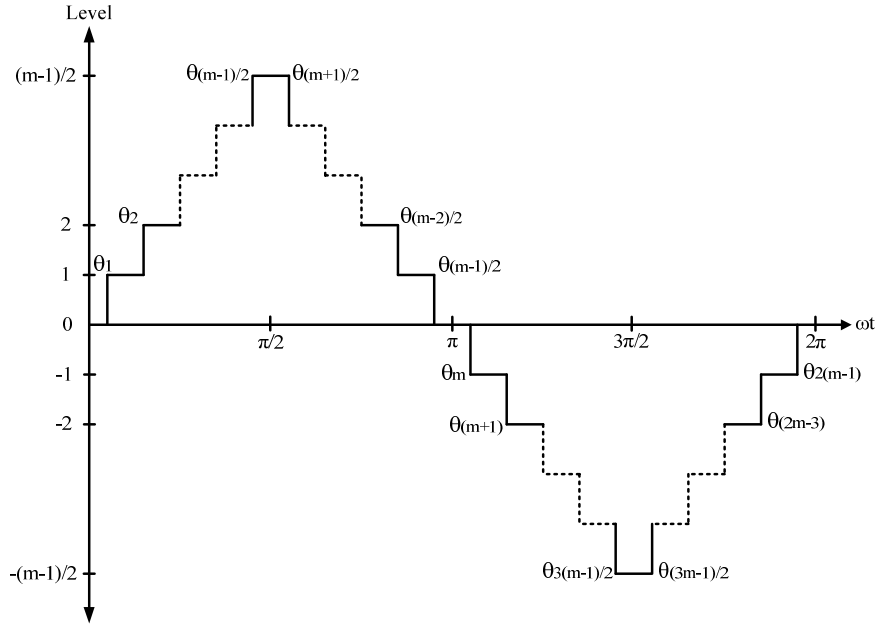

Fig. 2. Output voltage waveform for multilevel inverter.

\section{1) Half-Equal-Phase (HEP) Method}

To obtain a good quality output voltage waveform from multilevel inverter, the HEP method has been introduced for determining the switching angles [10]. The main switching angles are calculated by the following formula:

$$
\theta_{i}=i\left(\frac{180^{\circ}}{m+1}\right)
$$

\section{2) Feed-Forward (FF) Method}

There is wider gap between the positive half-cycle and the negative half-cycle by using the HEP method [10]. In order to reduce the gaps, another method is derived to determine the main switching angle which is knows as Feed-Forward method. The main switching angles are in the range $(0-\pi / 2)$, which is determined by the following formula:

$$
\theta_{i}=\frac{1}{2} \sin ^{-1}\left(\frac{2 i-1}{m-1}\right)
$$

\section{3) Selective Harmonic Elimination Pulse Width} Modulation (SHEPWM) Method

The SHEPWM method is widely used to control multilevel inverter and produced output voltage with low THD [11-13].

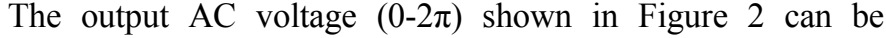
represented mathematically in a Fourier series as given by the following equation:

$$
v_{\text {out }}(\omega t)=\sum_{i=1,3,5, \ldots}^{\infty} \frac{4 V_{D C}}{i \pi}\left[\cos \left(\mathrm{i} \theta_{1}\right)+\cdots+\cos \left(\mathrm{i} \theta_{N}\right)\right] \sin (\mathrm{i} \omega t)
$$

The peak voltage of each $i^{\text {th }}$ harmonic component is given by the following formula:

$$
V_{p(\mathrm{i})}=\frac{4 V_{D C}}{i \pi}\left[\cos \left(\mathrm{i} \theta_{1}\right)+\cos \left(\mathrm{i} \theta_{2}\right)+\cdots+\cos \left(\mathrm{i} \theta_{N}\right)\right]
$$

The SHEPWM equations can be written with the desired fundamental peak voltage of $\mathrm{V} 1$ and peak voltage of higher order harmonics are zero. 


$$
\begin{aligned}
& V_{1}=\frac{4 V_{D C}}{\pi}\left[\cos \left(\theta_{1}\right)+\cos \left(\theta_{2}\right)+\cdots+\cos \left(\theta_{N}\right)\right] \\
& 0=\cos \left(3 \theta_{1}\right)+\cos \left(3 \theta_{2}\right)+\cdots+\cos \left(3 \theta_{N}\right) \\
& \quad \vdots \\
& 0=\cos \left((2 N-1) \theta_{1}\right)+\cos \left((2 N-1) \theta_{2}\right)+\cdots+\cos \left((2 N-1) \theta_{N}\right)
\end{aligned}
$$

By solving the SHEPWM equation sets given by (10), switching angles at fundamental frequency can be obtained, with the elimination of higher order harmonics.

\section{RESULTS AND DISCUSSION}

In this section, simulation results are presented for 9-level cascaded battery-boost inverter using three switching angle arrangement techniques at different power factor load (i.e., 1.0, 0.75 and 0.50 ). PSIM software is accurate simulator for this task. The cascaded battery-boost multilevel inverter is simulated for 9-level with a DC voltage supply of $120 \mathrm{~V}$. The data of simulation is analyzed based on the comparison of THD resulting from the HEP, FF, and SHEPWM switching techniques. The switching angles for the 9-level cascaded battery-boost inverter are generated by using switching angle arrangement techniques such as: HEP, FF, and SHEPWM as shown in Table II.

TABLE II. SWITCHING ANGLES FOR 9-LEVEL CASCADED BATTERYBOOST INVERTER.

\begin{tabular}{|c|c|c|c|}
\hline Angle & HEP Method & FF Method & SHEPWM Method \\
\hline$\theta_{1}$ & 18 & 3.59 & 10.02 \\
\hline$\theta_{2}$ & 36 & 11.02 & 22.14 \\
\hline$\theta_{3}$ & 57 & 19.34 & 40.75 \\
\hline$\theta_{4}$ & 72 & 30.53 & 61.77 \\
\hline$\theta_{5}$ & 108 & 149.47 & 118.23 \\
\hline$\theta_{6}$ & 126 & 160.66 & 139.25 \\
\hline$\theta_{7}$ & 144 & 168.98 & 157.86 \\
\hline$\theta_{8}$ & 162 & 176.41 & 169.99 \\
\hline$\theta_{9}$ & 198 & 183.59 & 190.02 \\
\hline$\theta_{10}$ & 216 & 191.02 & 202.14 \\
\hline$\theta_{11}$ & 234 & 199.34 & 220.75 \\
\hline$\theta_{12}$ & 252 & 210.53 & 241.77 \\
\hline$\theta_{13}$ & 288 & 329.47 & 298.23 \\
\hline$\theta_{14}$ & 306 & 340.66 & 319.25 \\
\hline$\theta_{15}$ & 324 & 348.98 & 337.86 \\
\hline$\theta_{16}$ & 342 & 356.41 & 349.99 \\
\hline
\end{tabular}

Figure 3 shows the output voltage waveforms for the 9level cascaded battery-boost inverter. The output voltage waveforms were obtained using three different switching angle arrangement techniques mentioned before at different power factors of 1.0, 0.75, and 0.50. From Figure 3, it is ascertained that the value of the output voltage was $\pm 120 \mathrm{~V}$ for the HEP, FF, and SHEPWM methods at three different power factors.

The current waveforms for 9-level cascaded battery-boost inverter at identical power factors are shown in Figures 4-6. The output voltage and current waveforms were obtained using the HEP, FF, and SHEPWM methods at power factors of 1.0, 0.75 , and 0.50 . Figure 4-6 shows that the output current was $\pm 12 \mathrm{~A}$ for HEP, FF, and SHEPWM method at power factor 1.0. When the power factor was decreased to 0.75 , the output currents were decreased to $\pm 8.2 \mathrm{~A}, \pm 10.8 \mathrm{~A}$ and $\pm 9 \mathrm{~A}$ for HEP, $\mathrm{FF}$, and SHEPWM method, respectively. When the power factor was decreased to 0.50 , the output currents were decreased to $\pm 5.2 \mathrm{~A}, \pm 6.08 \mathrm{~A}$ and $\pm 6 \mathrm{~A}$ for $\mathrm{HEP}, \mathrm{FF}$, and SHEPWM method, respectively. From these results, it was concluded that the output current decreases when the power factor decreases.
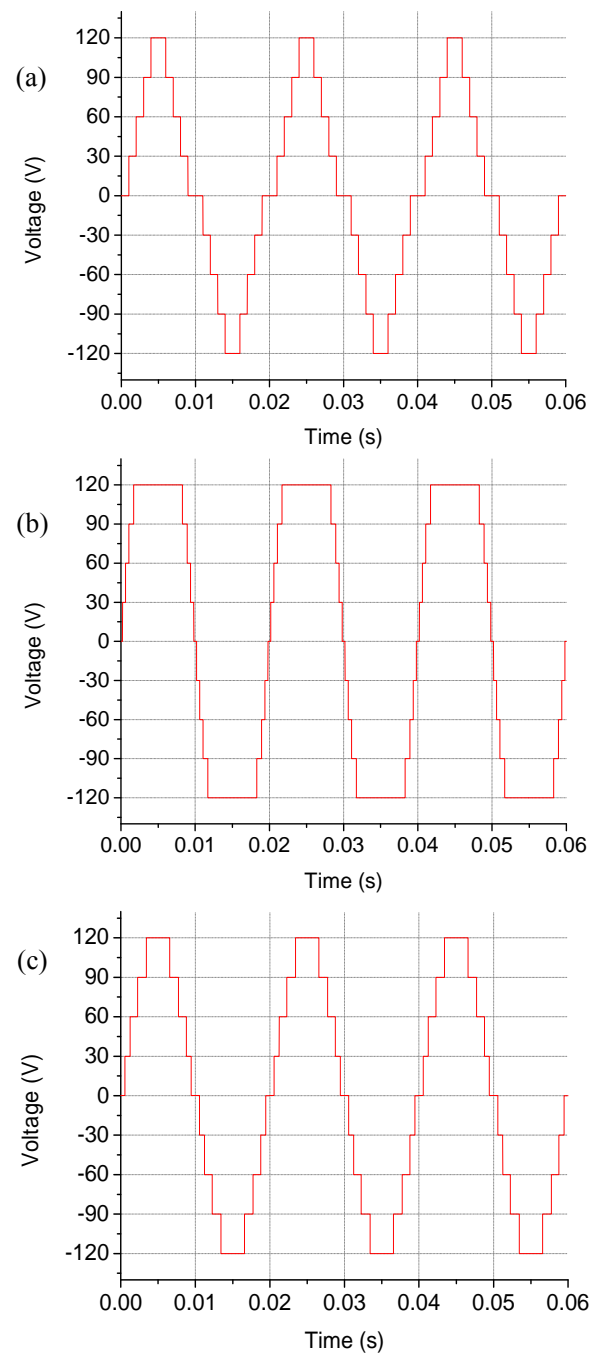

Fig. 3. Voltage output waveform with power factor 1.0, 0.75, 0.50: (a) HEP method (b) FF method (c) SHEPWM method.

Figure 7 shows the results of THD of the 9-level cascaded battery-boost inverter and Figure 8 shows the results of current THD with power factors of $1.0,0.75$ and 0.50 , respectively. The results of voltage THD at power factors of 1.0, 0.75, and 0.50 are demonstrated in Figure 7 , which shows that the voltage THD are the same for each power factor as the function of the inductor is to filter the current distortion. Thus, the inductive load only affects the THD of the current; it does not affect the THD of the voltage at all. From Figure 8, it is revealed that the current THD decreased slightly for each switching angle arrangement technique as the power factor decreased from 1.00 to 0.50 . With a power factor of 1.0 , where the load is purely resistive, the level of resultant current THD for HEP, FF and SHEPWM methods are $22.05 \%, 21.44 \%$ and $10.15 \%$, respectively. With a power factor of 0.75 the level of 
resulting current THD for HEP, FF and SHEPWM methods are $8.84 \%, 9.68 \%$ and $1.56 \%$, respectively. Similarly, with power factor 0.50 the level of resultant current THD for HEP, FF and SHEPWM methods are $7.08 \%, 7.75 \%$ and $1.23 \%$, respectively.

(a)
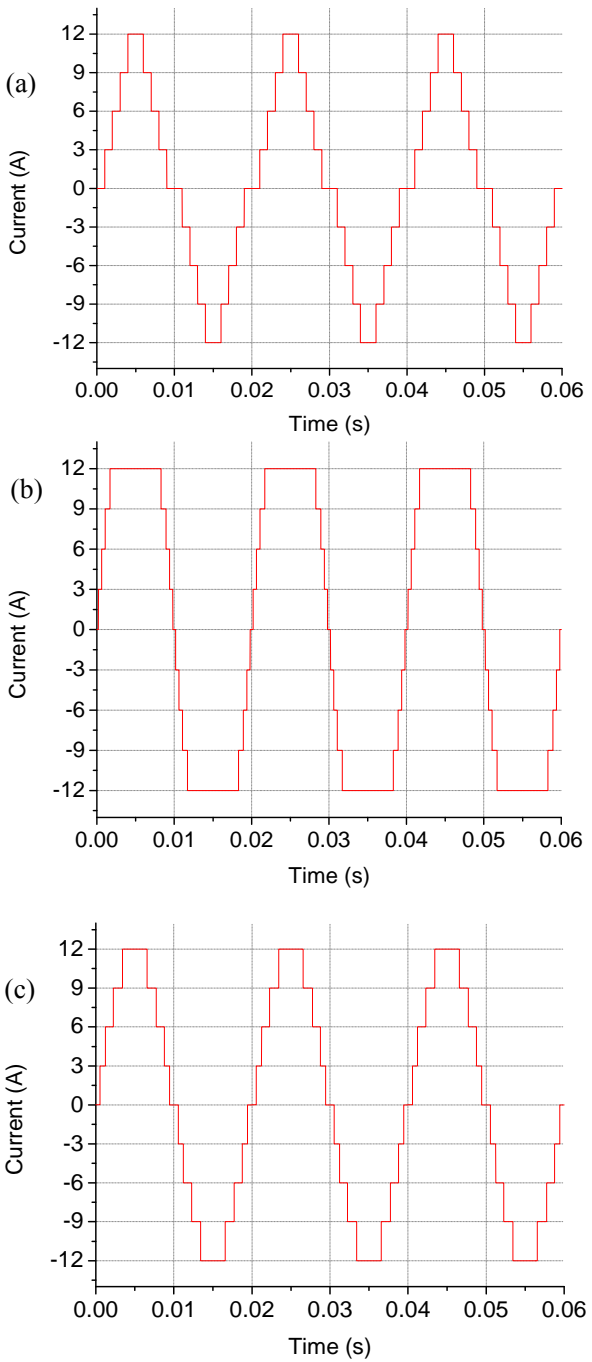

Fig. 4. Current output waveform with power factor 1.0: (a) HEP method (b) FF method (c) SHEPWM method.

The simulation results of the 9-level cascaded battery-boost inverter indicated that when the power factor decreases from 1.0 to 0.75 , for the HEP and the FF method, the current THD declined sharply to $60 \%$ approximately. Conversely using the SHEPWM method, the THD decreased to $85 \%$. Furthermore, when the power factor was decreased from 0.75 to 0.50 using HEP, FF and SHEPWM switching angle arrangement techniques, the current THD decreased sharply to $20 \%$. Finally from the overall discussion of the outcome of the research it can be concluded that when the value of power factor decreases, the current THD will decrease and the output waveform will become smoother.
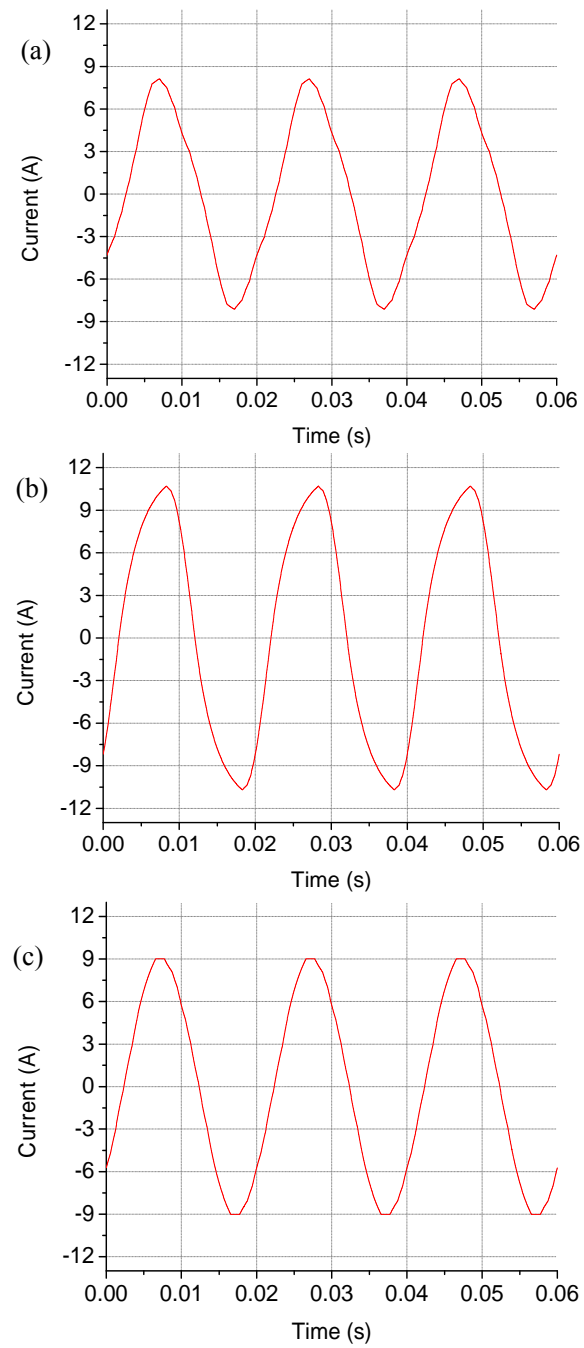

Fig. 5. Current output waveform with power factor 0.75: (a) HEP method (b) FF method (c) SHEPWM method

\section{CONCLUSION}

It is clearly shown that the selection of the switching techniques is an important factor for such a multilevel inverter. Without the proper switching angle arrangement techniques implemented, the output voltage distortion of the inverter can become worse. Consequently, the comparison of three switching angle arrangement techniques has been performed to identify the method, which yields the lowest THD for the 9level cascaded battery-boost inverter. Based on simulation results, it can be concluded that the voltage THD for HEP, FF, and SHEPWM switching angle arrangement techniques was the same at every power factor used in this research. However, the current THD was different for HEP, FF, and SHEPWM at different load power factors $(1.0,0.75$ and 0.50$)$ due to the inductive load. Furthermore, among three switching angle arrangement techniques, the SHEPWM switching angle arrangement technique has the lowest voltage and current THD compared to the other two. Due to the lowest THD the shape of voltage and current output waveform is more 
sinusoidal. On the other hand, the 0.50 power factor provides the lowest current THD compared to 1.0 and 0.75 .
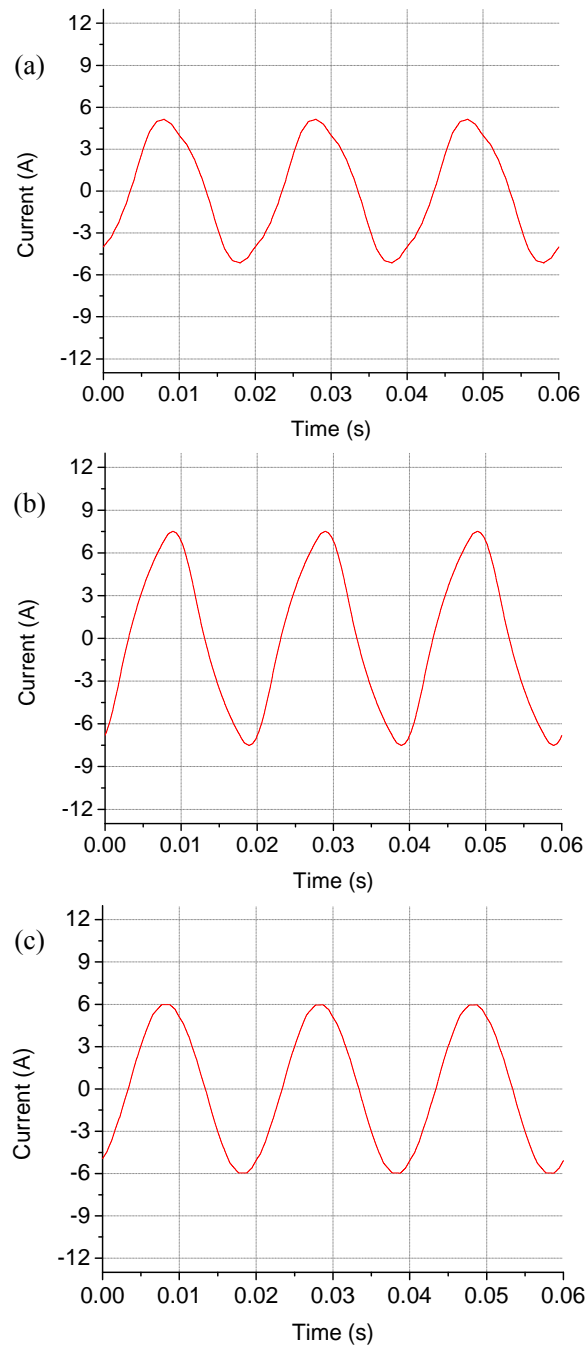

Fig. 6. Current output waveform with power factor 0.50 (a) HEP method (b) FF method (c) SHEPWM method

Total Harmonic Distortion (THD)

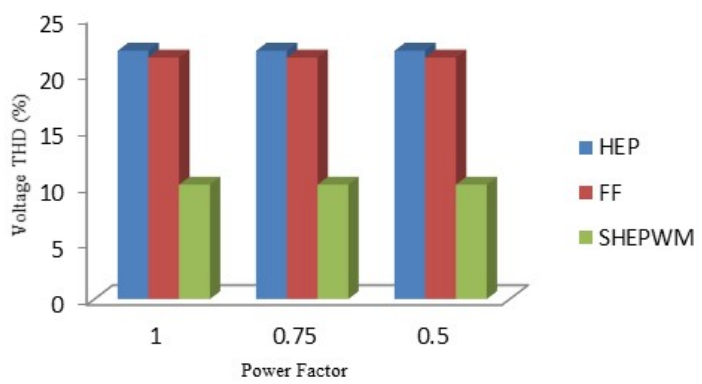

Fig. 7. Voltage THD of the 9-level cascaded battery-boost inverter.
Total Harmonic Distortion (THD)

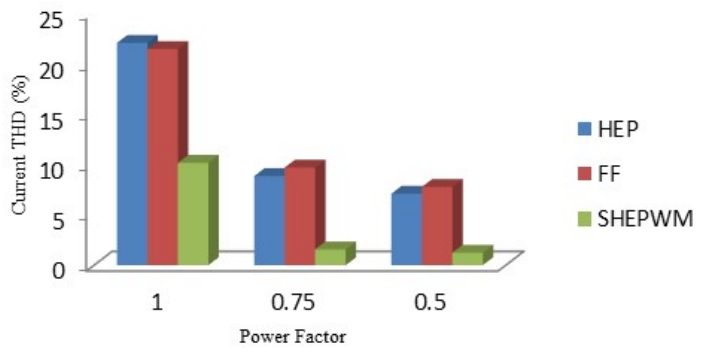

Fig. 8. Current THD of the 9-level cascaded battery-boost inverter.

\section{REFERENCES}

[1] T. Demirdelen, R. I. Kayaalp, M. Tumay, "A modular cascaded multilevel inverter based shunt hybrid active power filter for selective harmonic and reactive power compensation under distorted/unbalanced grid voltage conditions", Eng. Technol. \& Appl. Sci. Res., Vol. 6, No. 5, pp. 1133-1138, 2016

[2] S. Daher, J. Schmid, F. L. M. Antunes, "Multilevel Inverter Topologies for Stand-Alone PV Systems", IEEE Trans. Power. Electron., Vol. 55, pp. 2703-2712, 2008

[3] A. K. Panda, S. S. Patnaik, "Analysis of cascaded multilevel inverters for active harmonic filtering in distribution networks", Int. J. of Electric. Power \& Energy Syst., Vol. 66, pp. 216-226, 2015

[4] H. Rashid, Power Electronics: Circuits, Devices, and Applications, Prentice Hall, 2004.

[5] B. Nayak, S. S. Dash, "Performance analysis of different control strategies in a z-source inverter", Eng. Technol. \& Appl. Sci. Res., Vol. 3, No. 2, pp. 391-395, 2013

[6] G. N. Rao, P. S. Raju, K. C. Sekhar, "Harmonic elimination of cascaded H-bridge multilevel inverter based active power filter controlled by intelligent techniques", Int. J. of Electric. Power \& Energy Syst., Vol. 61, pp. 56-63, 2014

[7] E. Babaei, M. F. Kangarlu, M. Sabahi, M. R. A. Pahlavani, "Cascaded multilevel inverter using sub-multilevel cells", Electric Power Systems Research, Vol. 96, pp. 101-110, 2013

[8] L. Jih-Sheng, P. Fang Zheng, "Multilevel converters-a new breed of power converters", IEEE Trans. Industry Appl., Vol. 32, pp. 509-517, 1996

[9] M. Sadikin, T. Senjyu, A. Yona, "High-frequency link DC for power quality improvement of stand-alone PV system in cascaded multilevel inverter", Power Electronics and Drive Systems, pp. 597-601, 2013

[10] F. L. Luo, "Investigation on best switching angles to obtain lowest THD for multilevel DC/AC inverters", 8th IEEE Conference on Industrial Electronics and Applications (ICIEA), June 19-21, 2013

[11] K. Corzine, Y. Familiant, "A new cascaded multilevel H-bridge drive", IEEE Trans. Power. Electron., Vol. 17, No. 1, pp. 125-131, 2002

[12] K. Ganesan, K. Barathi, P. Chandrasekar, D. Balaji, "Selective Harmonic Elimination of Cascaded Multilevel Inverter Using BAT Algorithm”, Procedia Tech., Vol. 21, pp. 651-657, 2015

[13] V. K. Gupta, R. Mahanty, "Optimized switching scheme of cascaded Hbridge multilevel inverter using PSO”, Int. J. of Electric. Power \& Energy Syst., Vol. 64, pp. 699-707, 2015 